\title{
Legal Regulation of the Advertising Blocking Feature-A Chinese Perspective
}

\author{
Fei Lanfang \\ Faculty of law \\ Jinan University \\ Guangzhou, China \\ fei27@hotmail.com
}

\author{
Zhou Peng \\ Faculty of Computer Science \\ Dongguan University of Technology \\ Dongguan, China \\ zhoupeng@hotmail.com
}

\begin{abstract}
Ad blocking tools have become part of the unfair competition debate in China. Leading Chinese online video companies have initiated several lawsuits against Web browsers and software developers that provide add-ons or similar tools that let people avoid advertisements. Chinese courts have taken a strong stance in support of the online video industry's ad-based business model, ruling that Web browsers and software that provide ad avoidance plug-ins are liable for unfair competition. This paper reviews those cases dealing with ad blocking tools and explores the judicial approach taken by the Chinese courts as well as the implications of the courts' ruling on the related industry.
\end{abstract}

Keywords-Ad blocking feature; unfair competition; online video sites; Chinese rulings

\section{INTRODUCTION}

Advertisement (Ad) blocking is removing or altering advertising content on a webpage. Ad blocking tools range from fast-forward buttons on remote controls to software components that add a specific ad blocking feature to an existing computer program, such as Web browser extensions or independent software. While Internet users applaud such tools because they can provide quicker loading and cleaner looking Web pages free from advertisements, ad-supported content providers view the tools as a threat to their business model. In the face of this threat, content providers turned to the law, asking the courts to protect their ad-based business model against ad-blocking technologies.

The Chinese courts responded favorably. The courts explicitly ruled that Web browsers, software or hardware with advertising filtering functions designed to skip or block legitimate advertisements were illegal, constituting unfair competition. Generally, Chinese courts consider the removal of advertisements from legalized content, especially online videos or games, as a sort of technological interference for the purpose of unjust enrichment. Specifically, the courts ruled that a Web browser or any other product could not filter advertisements automatically or otherwise as a legitimate business model expect when done for a specific public purpose. The Chinese judicial stance is a significant exploration of the legal boundaries of developing and applying ad blocking tools and has an important impact on the development of ad related industries.
This paper proceeds by outlining the conflict that has arisen out of the introduction of ad blocking functions in the Chinese new media market, examining a number of decisions by the Chinese courts that have dealt with determining the legitimacy of anti-advertising tool providers, and comparing the approach taken by the Chinese courts to approaches adopted by other jurisdictions, while evaluating the implications of the Chinese approach. The final part is a general conclusion.

\section{Conflict ARISES OUT OF THE AD Blocking Function IN CHINA}

China is home to the world's largest new media market, propelled by the country's growing Internet penetration and a vibrant range of new media applications. The fast expansion of new media has fuelled a surge in the amount and variety of online advertisement. According to the latest data released by the technology consulting firm iResearch, revenue from China's online advertising market reached 37.87 billion Yuan in Q1 2015, increasing 36.6\% from a year earlier [1].

The online video industry is a typical example of the adsupported business model of the new media industry. Another report released by iResearch, shows that revenue from China's online video market in 2014 reached 24.50 billion Yuan, an 80.3\% increase over the prior year. In the increased 10.91 billion Yuan online video revenue, advertising revenue and other business revenue, respectively, contributed $49.3 \%$ and $33.9 \%$. Advertising remained the main income source for online videos. While China's online-video market is the largest and most innovative in the world, it is also the most competitive. Google's YouTube video service is blocked in China, but local companies, including Youku(www.youku.com) run by Union Group, Iqiyi(www.iqiyi.com) run by Iqiyi Co., Ltd, LeTV(www.letv.com) run by Leshi Internet Information \&Technology Corp., Beijing, QQTV(http://v.qq.com) run by Tencent, Inc., and Sohu(www.suhu.com )run by Sohu Inc. are wildly popular. Under pressure from unreliable viewer numbers, high royalty costs and management fees, the online video site companies increased the time and frequency of advertisement to increase revenue.

Naturally, users dislike online video ads more than TV commercials. Responding to the demand of internet users wishing to avoid ubiquitous online advertising, various ad 
avoidance tools were developed including AdBlock Plus, Ad Block, AdMuncher, Adsafe and so forth. Usually attached as plugins to a browser or application platform, the ad blocking service enables the user to remove the very advertisements that make the content they wish to access possible (HASKINS, 2008). This initiated a heated conflict among software and browser providers, advertising agencies, and ad-supported businesses in China and in many other Countries in the world. In 2012, a top Chinese security company, Kingsoft Technology Co., Ltd. (Kingsoft), released its "mobile drug tyrants" software with a feature designed to shield and intercept mobile ads. In response, 19 advertising agencies and mobile application developers boycotted Kingsoft and issued a joint statement saying that Kingsoft's actions constituted unfair competition. In 2014, Google's Maxthon launched its latest browser with the ability to skip video ads - the browser was blocked by several major online video companies in China. Because ad blocking features were having a disastrous impact on the ad-supported business model used by online video sites, the owners of these sites finally brought the dispute before the Chinese courts. Up to now there have been eight lawsuits between online video sites and advertising blocking tool providers. The following section presents typical cases and key rulings [2].

\section{Review of Cases Involving AD-Blocking Feature}

The first lawsuit concerning the use of anti-advertising functions was brought by the biggest Chinese search engine company, Baidu Technology Co., Ltd. (Baidu), against the biggest Chinese internet security company, Qihoo 360 Technology Co., Ltd. (Qihoo), in August 2013 before the Beijing West District Court. Baidu asserted that Qihoo maliciously enticed Baidu's users to use ad blocking add-ons available in Qihoo's security browser and therefore, was engaged in unfair competition practices. The court ruled for Baidu, holding that Qihoo interfered with the operation of Baidu's search engine by using advertising plug-in as a publicity stunt to promote its security browser and by maliciously leading consumers to use the plug-in. Later, in the landmark case Tencent Technology (Shenzhen), Ltd. vs. Qihoo 360 Technology Co., Ltd. (Tencent vs. Qihoo), Qihoo released software called “QQ Guard”, which targeted QQ- the flagship instant messaging software developed by Tencent. QQ Guard rates the health and safety of QQ, speeds it up, shows its suspicious activity, removes its advertisements, deletes the value-added plug-ins embedded by programmers and prevents computer viruses from stealing account information. The Supreme People's Court (SPC) of China did not agree that tolerating ads and other value-added plug-ins and pop-ups are necessary "considerations" for obtaining a free Instant Message (IM) service, as was held by the lower court. However, the SPC agreed that destroying a competitor's commercial model and software such that consumers could enjoy a free IM service without browsing ads and plug-ins extended beyond the interests of the consumers.

Despite that the above two cases concerned advertising on a search engine and on instant messaging software, the main battleground over anti-advertising services has been the online video industry. The issue of justification of the advertising blocking function had not been fully addressed until Union Information Technology (Beijing) Co., Ltd. vs. Kingsoft (Beijing) Security Software Co., Ltd. et al. ('Union vs. Kingsoft”). In that case, Union, which is well known for its video content providing services, claimed that the Cheetah browser, developed by the defendant, provided an "ad-block plus" function to the end user. When accessing the site (http://www.youku.com) through the Cheetah browser, the end user could filter the advertisements displayed by Union. Union asserted that the use of Cheetah's ad-block plus function deprives Union of income from advertising on the Youku site and constitutes unfair competition.

Kingsoft argued that, among other factors, browsers that are capable of filtering online advertising are the industry standard and that the ad-filtering feature that comes with the Cheetah browser is configured as disabled by default, thus requiring users to initiate ad-filtering. The Cheetah browser does not make the choice for the consumers; it is only a tool, and providing that tool is consistent with the principle of technological neutrality. In addition, Kingsoft asserted that the users of Youku did not want the advertising that came with the video. The ad-block plug-in was simply a response to consumer demand.

The Beijing 2nd Intermediate Court did not accept the public interest defence. The court first confirmed that the AUCL aims to create legal and orderly competition, which must ultimately benefit the public interest. Then, the court stated that Kingsoft did not develop and provide the browser for the purpose of public interest. Although the ad-block plus software associated with the browser met the requirements of some users, it would have a negative impact on the long-term welfare of consumers from two aspects:

First, the ad-blocking plug-in would destroy the free video plus advertising model of the business and cause the site operator to adopt a pay-per-view model, which would result in a higher cost to consumers who watch videos online. Currently, online streaming sites have two business models: free video plus advertising and pay-per-view. The free video plus advertising model, in which users pay only the cost of their time watching ads but do not pay money, is the most common. The site allows users to watch free videos, not because the site does not have commercial value but because the advertising revenue, to a great extent, offsets the cost of purchasing videos and other operational overhead. If the court confirmed the legality of the Cheetah browser with ad-block plus, the online video sites would have difficulty obtaining advertising revenue, which would cause the main business model to change from free video plus advertising to pay-per-view. This shift would cause users to pay an economic cost and would not allow them to choose between paying with time or paying with money. It would be difficult to say that this shift would be beneficial to users.

Second, the ad-blocking plug-in would kill the demand for video streaming sites in the long run because it would be difficult for the consumer to accept the pay-per-view model. In the market economy, the operators' choice of business model cannot be maintained without the consumers' acceptance. Although the free video plus advertisement model is not the 
only way to generate profits, consumers are less likely to accept an alternative business model, i.e., the fee-charge model. If video sites cannot adopt the free video plus advertising model and assuming that users would not accept the fee-charge model, it is probable that the online video industry would not survive beyond the near future. Though video sites are not the only avenue for watching videos, the extinction of such sites would surely reduce the likelihood of finding videos and would therefore compromise the interest of users.

The positive attitude towards online video sites was followed by other courts in dealing with similar disputes. Table 1 shows advertising blocking related litigation initiated by online site companies.

TABLE I. ADVERTISING BLOCKING RELATED CASES LIS

\begin{tabular}{|l|l|c|c|}
\hline \multirow{2}{*}{ YEAR } & \multicolumn{3}{|c|}{ CASES } \\
\cline { 2 - 4 } 2013 & \multicolumn{1}{|c|}{ CASE NUMBER } & \multicolumn{1}{|c|}{ ISSUE } & RULING \\
\hline \multirow{2}{*}{2014} & $\begin{array}{l}\text { Baidu vs. Qihoo 360; } \\
\text { Union vs. Kingsoft }\end{array}$ & $\begin{array}{l}\text { Advertisement } \\
\text { removal feature }\end{array}$ & $\begin{array}{c}\text { Favorable } \\
\text { ruling for } \\
\text { search engine } \\
\text { and video site }\end{array}$ \\
\hline \multirow{2}{*}{2015} & $\begin{array}{l}\text { Letv vs. Baidu Cloud } \\
\text { TV; } \\
\text { Iqiyi vs. Jiluyou; } \\
\text { Iqiyi vs. Letv; }\end{array}$ & $\begin{array}{l}\text { Advertisement } \\
\text { removal feature }\end{array}$ & $\begin{array}{c}\text { Favorable } \\
\text { ruling for } \\
\text { video site or } \\
\text { pending }\end{array}$ \\
& $\begin{array}{l}\text { Iqiyi vs. Adsafe; } \\
\text { Iqiyi vs. UC BreT; } \\
\text { Iqiyi vs. Sougouser; }\end{array}$ & $\begin{array}{l}\text { Advertisement } \\
\text { removal feature }\end{array}$ & $\begin{array}{c}\text { Favorable } \\
\text { ruling for } \\
\text { video site or } \\
\text { pending }\end{array}$ \\
\hline
\end{tabular}

Among the above cases, Adsafe is a piece of ad skipping software, Kingsoft's Cheetah Browser and Sougou's Sougou browser are Web browsers with ad skip extensions, UC Browser is mobile web browser with ad blocking extension, Baidu Cloud TV, LeTV, MoreTV are online TV boxes with ad removal functions, Jikejike's router and Jiluyou's router are hardware devices with advertising removal features. According to the courts, not only browsers with ad block add-ons but also any platform, software or platform providing ad filtering service, regardless whether the application is uploaded by a third party or produced by the platform or hardware, are liable for the unfair interference of the business model of adsupported online video sites. Obviously, the Chinese courts show a solid stance in support of online video sites.

\section{Evaluation of the Approach TAKen by Chinese COURTS}

The ad blocking function has initiated controversies not only in China. By its nature, advertising filtering products have a commercial skip effect. Ad-supported companies have long turned to the courts to squelch products that let consumers block or skip ads in many jurisdictions [3]. With the growth of the functionality and popularity of anti-advertising software and add-ons, current legal fights have emerged over Web browser add-ons or other tools that let people avoid advertisements [4].

U.S. courts, following the judicial approach established by the Sony case in 1982, take a broad approach towards ad blocking and skip features that automatically remove embedded advertisements [5]. In Overstock vs. SmartBargains, the Supreme Court of Utah held that the rules dictating that pop-up ads appear in a separate window on a competitor's website do not constitute unfair competition or tortuous interference under Utah law. The Court stated that competitors inevitably damage one another in the struggle for personal advantage and insisted that the law offers no remedy for those damages - even if it is intentional-because such damages are an inevitable by-product of competition. Additionally, in New.net, Inc. v. Lavasoft, a federal district court denied plaintiff New.net Inc.'s motion for a preliminary injunction, which sought to enjoin defendant Lavasoft from both informing consumers via its Ad-Aware software that NewDotNet, a software program distributed by the plaintiff, was installed and running on their computers, and providing consumers with tools that enable them to uninstall that software if they so desire. The court denied the plaintiff's motion, finding that by informing consumers that NewDotNet was installed and running on their computers, Lavasoft was engaging in speech about a matter of public interest protected by the First Amendment. In 2009, a federal appeals court, in the first decision of its kind, ruled that companies providing malware, spyware and adware blocking services are immunized by the Communications Decency Act of 1996 from lawsuits claiming unfair business practices. The court concluded that "a provider of access tools that filter, screen, allow, or disallow content that a provider or user considers obscene, lewd, lascivious, filthy, or excessively violent, harassing or otherwise objectionable is protected from liability". In 2012, a judge of a U.S. District Court refused to grant Fox Broadcasting's request for a preliminary injunction against Dish Network's advertising-skipping DVR services known as "AutoHop" and "PrimeTime Anytime." The district court's ruling was later confirmed by the U.S. Court of Appeals in July 2013. The court also came to the same conclusion regarding ABC Televisions' request on September 2013[6].

In EU, the issue is discussed in the context of the unfair competition law. According to the EU courts, business models are generally not protected by law, although some specific business methods are patentable. In one case, the German High Court did not consider the sale of the "television fairy" to be a breach of competition law, as set out in $§ 1$ UWG. It said that $\S 1$ UWG did not guarantee companies a general and comprehensive right to protection from interference from third parties [7]. The whole nature of competition was such that new technical developments were constantly altering market conditions. The German Court further noted that the damage suffered by ad-blocking tools could be eliminated by other avenues. Additionally, in a recent case brought by leading broadcasters RTL and ProSieben against Ad-Block Plus, the court repeated that it had determined that AdBlock Plus could not be considered anti-competitive because Internet users were free to choose whether to install the software, thereby leaving sufficient scope for publishers to find an alternative audience for advertising [8].

The Chinese courts' approach, despite relying on the same legal ground as the German Courts, comes to an opposite conclusion. The first reasoning of the Chinese courts is that the ad-supported business model is a legitimate model and should 
be protected by law. The second reasoning of the Chinese courts is that browsers with ad-block plug-ins would be detrimental to consumers in the long run because the legitimate business model of video sites would be strangled. There are some deficiencies in this reasoning. First, SPC, in Tencent vs. Qihoo, highlighted the choice of consumers and that consumers' appreciation of free services has no correlation to the extra time or tolerance of other services. However, in Union vs. Kingsoft, the court stated that the fact that consumers could freely choose to configure the ad-blocking plug-in was not important in determining the long-term public interest. If the consumer has no obligation to watch the ads, why should the consumer be unable to avoid watching them using the adblocking plug-in? Second, there are similar arbitrary assumptions in the ruling of Union vs. Kingsoft. The court said that the online video industry would be doomed by ad-blocking plug-ins because consumers would not accept a pay-to-view model. How did the court know that consumers would not accept to pay-to-view video? If there is no choice, it is highly possible that a reasonable consumer would pay to watch videos that he likes. In addition, while there is little doubt that online video sites have lost revenue due to ad-blocking tools, the evidence are insufficient to estimate the amount of those losses.

\section{CONCLUSION}

The Internet has emerged as an incredibly important advertising medium. It is believed that the internet will eventually overtake traditional TV and cable as the preferred method of media consumption [9]. Thus, the issue of users who are able to skip or bypass ads is an important concern for content producers to face. The Chinese judicial approach sets an important precedent and provides an indication of the approach that other courts are likely to consider in the future. The outcomes of these cases are relevant not only to online video sites and browsers but also to any business that relies on advertisements for revenue, such as search engines or other internet content hosts.

\section{REFERENCES}

[1] Beddoes Minton Zanny. Online video in China:The Chinese stream. The Economist, Vol.61, pp. 34, 2011.

[2] Fei Lanfang. Battle in the name of privacy and security: A comment on Tencent vs. Qihoo. Computer Law\& Security Review, Vol. 30, pp.591592, 2014.

[3] Gershman J. Law professors back dish in 'AutoHop' war. The Wall Street Journal, Vol. 20, pp. 23-24.2015.

[4] Hemmer L.John. The Internet Advertising Battle: Copyright Laws Used to Stop the Use of Ad-Blocking Software. Temple Journal of Sci. Tech \& Envil Law,Vol. 26, pp. 480, 2004.

[5] Jilian Vallade, Adblock Plus and the Legal Implications of Online Commercial-Skips, Rutgers Law Review, Vol61(3), pp.823-824, 2009.

[6] Kim Myunsoo, \& Lee Byungtae. Analysis of an advertisement based business model under technological. Electronic Commerce Research and Applications . Vol.14, pp. 170, 2015.

[7] Walbesser L. Jordan, Blocking Advertisement Blocking: The War Over Internet Advertising and The Effect on Intellectual Property, Intell. Prop. \& Tech. L.J. ,Vol. 23, pp. 19, 2009.

[8] Adisdorfer, \& H.P.Hsu, Innovation to survive: The effect of technology compeititon on corporate bankruptcy. Financial Management, Vol.11, pp.23, 2011.

[9] Bessen.J, \& E Maskin, Sequential innovation patents and imitation. The RAND Journal of Economics,Vol.40, pp. 611-612, 2009. 